\title{
Lead Chromate
}

National Cancer Institute

\section{Source}

National Cancer Institute. Lead Chromate. NCI Thesaurus. Code C45891.

A yellow, orange or red colored, crystalline, inorganic compound that emits toxic chromium fumes upon heating. Lead chromate is highly corrosive and is a strong oxidizing agent. This substance is used in printing inks, paints and to color vinyl, rubber and paper. Lead chromate primarily affects the lungs causing shortness of breath, bronchitis, pneumonia and asthma but can also affect the gastrointestinal tract, liver, kidneys and immune system. This substance is a known human carcinogen and is associated with an increased risk of developing lung cancer and cancer of the sinonasal cavity. ( $\mathrm{NCl05)}$ 